Article

\title{
Emulsion Formation and Stabilizing Properties of Olive Oil Cake Crude Extracts
}

\author{
Firdaous Fainassi ${ }^{1}$, Noamane Taarji ${ }^{1,2, *}$, Fatiha Benkhalti ${ }^{3}$, Abdellatif Hafidi ${ }^{1}$, Marcos A. Neves ${ }^{4}(\mathbb{D}$, \\ Hiroko Isoda ${ }^{4}$ and Mitsutoshi Nakajima ${ }^{4}$
}

1 Department of Biology, Faculty of Sciences-Semlalia, Cadi Ayyad University, Marrakech 40001, Morocco; fainassi.f@gmail.com (F.F.); a.hafidi@uca.ac.ma (A.H.)

2 Food and Medicinal Resource Engineering Open Innovation Laboratory, National Institute of Advanced Industrial Science and Technology (AIST), Tsukuba 305-0821, Japan

3 Sustainable Development and Health Research Laboratory, Cadi Ayyad University, Marrakech 40000, Morocco; benkhalti.f@gmail.com

4 Faculty of Life and Environmental Sciences, University of Tsukuba, Tsukuba 305-8572, Japan; marcos.neves.ga@u.tsukuba.ac.jp (M.A.N.); isoda.hiroko.ga@u.tsukuba.ac.jp (H.I.); nakajima.m.fu@u.tsukuba.ac.jp (M.N.)

* Correspondence: taarji.noamane@aist.go.jp

check for updates

Citation: Fainassi, F.; Taarji, N.; Benkhalti, F.; Hafidi, A.; Neves, M.A.; Isoda, H.; Nakajima, M. Emulsion Formation and Stabilizing Properties of Olive Oil Cake Crude Extracts. Processes 2021, 9, 633. https:// doi.org/10.3390/pr9040633

Academic Editors: Sebastián Sánchez Villasclaras and Juan Francisco García Martín

Received: 2 March 2021

Accepted: 30 March 2021

Published: 4 April 2021

Publisher's Note: MDPI stays neutral with regard to jurisdictional claims in published maps and institutional affiliations.

Copyright: (c) 2021 by the authors. Licensee MDPI, Basel, Switzerland. This article is an open access article distributed under the terms and conditions of the Creative Commons Attribution (CC BY) license (https:/ / creativecommons.org/licenses/by/ $4.0 /)$.

\begin{abstract}
The surface-active and emulsifying properties of crude aqueous ethanolic extracts from untreated olive oil cake (OOC) were investigated. OOC extracts contained important concentrations of surface-active components including proteins, saponins and polyphenols (1.2-2.8\%, 7.8-9.5\% and $0.7-4.5 \%(w / w)$, respectively) and reduced the interfacial tension by up to $46 \%\left(14.0 \pm 0.2 \mathrm{mN} \mathrm{m}^{-1}\right)$ at the oil-water interface. The emulsifying ability of OOC extracts was not correlated, however, with their interfacial activity or surface-active composition. Eighty percent aqueous ethanol extract produced the most stable oil-in-water $(\mathrm{O} / \mathrm{W})$ emulsions by high-pressure homogenization. The emulsions had average volume mean droplet diameters of approximately $0.4 \mu \mathrm{m}$ and negative $\zeta$-potentials of about $-45 \mathrm{mV}$, and were stable for up to 1 month of storage at 5,25 and $50{ }^{\circ} \mathrm{C}$. They were sensitive, however, to acidic $\mathrm{pH}$ conditions $(<5)$ and $\mathrm{NaCl}$ addition $(\geq 25 \mathrm{mM})$, indicating that the main stabilization mechanism is electrostatic due to the presence of surface-active compounds with ionizable groups, such as saponins.
\end{abstract}

Keywords: olive oil extraction by-product; interfacial tension; oil-in-water emulsion; protein; saponin; polyphenol

\section{Introduction}

Emulsifiers are one of the most important ingredients in food industry. They are utilized as stabilizers and/or encapsulants in many food products and beverages in which they provide multiple properties such as good dispersibility, prolonged stability and improved bioavailability of other ingredients [1]. Many emulsifiers used nowadays derive from the same chemical and/or enzymatic reactions that were primarily designed in the past for mass and economic production of these substances [1,2]. The current trend towards natural and sustainable production of food emulsions, however, has led manufacturers to find new natural alternatives to synthetic emulsifiers [2]. Plant-derived compounds such as proteins, saponins, polysaccharides and phospholipids have shown promising emulsifying properties in various food applications [2,3]. They can provide similar stabilizing properties as synthetic emulsifiers, but they are also criticized because of their extensive preparation/manufacturing procedures [4-6].

A new trend in the utilization of food emulsifiers suggest the use of crude plant surface-active extracts, obtained via simple extraction/fractionation steps, to produce stable emulsions. Agro-industrial by-products contain various surface-active substances with strong emulsifying properties and can be utilized, therefore, as a source of these ingredients. 
Sugar beet, Panax ginseng, oat bran, argan and bagasse by-products extracts have been successfully used, for example, to prepare stable oil-in-water $(\mathrm{O} / \mathrm{W})$ emulsions [7-12]. The active ingredients in these "crude" emulsifiers differ from one extract to another but they are, generally, attributed to a mixture of various surface-active components synergizing for an enhanced effect.

Olive oil processing by-products come in different forms and chemical profiles, depending on the olive ripening stage and the oil extraction method. In the traditional three-phase decanter systems, the solid waste is dry and contains significant contents of residual oil $(2-4 \%, w / w)$, while in the case of two-phase decanter systems, a high-humidity $(68-71 \%, w / w)$ semi-solid waste "Alperujo", here referred to as olive oil cake "OOC", is generated [13]. The major components found in olive solid by-products are polysaccharides (lignin 26-30\%, hemicellulose 7-9\% and cellulose 7-9\%, w/w), proteins $5-7 \%(w / w)$, fatty acids $5-8 \%(w / w)$ and polyphenols (oleuropein, hydroxytyrosol and tyrosol) [14]. Such chemical composition makes solid olive processing wastes stand out as a promissory source of bioactive and nutritional compounds, especially in response to the rising trend of finding natural alternatives to synthetic ingredients.

Despite their abundance and valuable composition, studies investigating the emulsifying capacities of olive solid wastes are scarce. Filotheou et al. [15] used alcohol-insoluble olive processing wastes as a source of surface-active components to prepare acidic and non-acidic model food emulsions. The emulsifying efficiency was mainly attributed to the synergy between the surface-active macromolecular components and smaller surfactants. Koliastasi et al. $[16,17]$ investigated the impact of partial and total composting on the surface-active composition and concluded that such treatments can produce emulsifiers with enhanced performances as compared to the extracts of non-composted materials. However, none of the previous studies have considered the use of crude extracts involving basic solid-liquid extraction from raw untreated material as emulsifiers. In this study, we evaluated the surface-active and emulsifying properties of various aqueous ethanolic extracts from olive oil extraction by-products. Our aim is to produce stable oil-in-water $(\mathrm{O} / \mathrm{W})$ emulsions using these extracts as sole emulsifiers.

\section{Materials and Methods}

\subsection{Materials}

Olive oil cakes (Picholine marocaine cultivar) obtained from a two-phase decanter system were provided by an industrial olive oil extraction unit in the region of Marrakech, Morocco. All other products were purchased from Wako Pure Chemical Industries, Ltd. (Osaka, Japan) unless stated elsewhere.

\subsection{Sample Preparation and Extraction Yields}

The samples $(100 \mathrm{~g})$ were added to fresh mixtures $(300 \mathrm{~mL})$ of distilled water and ethanol and stirred for $3 \mathrm{~h}$ at room temperature. The suspensions were then centrifuged at $2000 \times g$ for $30 \mathrm{~min}$, filtered using Whatman filter paper type 111A and vacuum evaporated at $40{ }^{\circ} \mathrm{C}$ and $16 \mathrm{hPa}$ (Eyela EVP-1100, Shanghai Co., Ltd., Shanghai, China) to remove solvent. The dried extracts were finally dispersed in distilled water, re-filtered using $0.45-\mu \mathrm{m}$ hydrophobic PTFE membrane filters (RephiLe Bioscience, Co., Ltd., Shuangbai, China) and freeze-dried at $-80^{\circ} \mathrm{C}$ and $4 \mathrm{~Pa}$ (Eyela FDH-2110, Tokyo Rikakikai Co., Ltd., Tokyo, Japan) to remove water. The yields of extraction (EY) were calculated as follows:

$$
\text { EY }(\% \text {, wet basis })=W_{1} / W_{0} \times 100
$$

where $W_{1}$ represents the weight of the extract after the freeze-drying and $W_{0}$ represents the weight of the fresh olive oil cake.

\subsection{Physicochemical Characterization}

Protein content was determined using a total nitrogen analyzer (UNICUBE, Elementer Ltd., Yokohama, Japan) with a nitrogen-to-protein conversion factor of 6.25. Saponins 
content was determined following the method of Zhaobao et al. [18], using oleanolic acid as standard (0-192 $\mu \mathrm{g})$. Phenolic compounds content was determined following the FolinCiocalteu method [19] using gallic acid as standard $\left(0.1-0.5 \mathrm{~g} \mathrm{~L}^{-1}\right)$. Interfacial tension was measured using the pendant drop method (PD-W, Kyowa Interface Science Co., Ltd., Saitama, Japan) at the soybean oil/water interface [10]. Particle size was determined using a dynamic light scattering particle size analyzer (Nano ZS, Malvern Instruments Ltd., Worcestershire, UK).

\subsection{Emulsion Preparation}

Coarse emulsions were prepared by homogenizing $0.1-5 \%(w / w)$ extract and $2.5-10 \%$ $(w / w)$ soybean oil at 10,000 rpm for 5 min (Polytron PT-3000, Kinematica Inc., Luzern, Switzerland). The coarse emulsions were then passed through a high-pressure homogenizer (NanoVater NV200, Yoshida Kikai Co., Ltd., Nagoya, Japan) at $100 \mathrm{MPa}$ for four passes and stored at $25^{\circ} \mathrm{C}$ until analysis.

\subsection{Emulsion Stability Evaluation \\ 2.5.1. Effect of $\mathrm{pH}$}

Emulsions were diluted with phosphate buffer solutions (10 mM) to obtain a final oil content of $2.5 \%(w / w)$. The $\mathrm{pH}$ was then readjusted to appropriate level (2-9), using $1 \mathrm{M}$ $\mathrm{HCl}$ or $\mathrm{NaOH}$, and the samples were stored for $24 \mathrm{~h}$ at $5^{\circ} \mathrm{C}$ before analysis [9].

\subsubsection{Effect of Ionic Strength}

Emulsions were diluted with phosphate buffer solutions $(10 \mathrm{mM})$ of appropriate $\mathrm{NaCl}$ concentration (50-800 $\mathrm{mM}$ ) to obtain a final oil content of $2.5 \%(w / w)$. The $\mathrm{pH}$ was then readjusted to 7 and the emulsions were stored at $5{ }^{\circ} \mathrm{C}$ until analysis [10].

\subsubsection{Effect of Long-Term Storage}

Sodium azide was added to the freshly prepared emulsions at a final concentration of $0.02 \%(w / w)$. The emulsions were then incubated for 30 days at 5,25 or $50{ }^{\circ} \mathrm{C}$ prior to analysis.

\subsection{Droplet Characterization}

Volume mean droplet diameter $\left(d_{4,3}\right)$ was measured using a static laser diffraction particle size analyzer (LS 13 320, Beckman Coulter, Brea, USA). Droplet charge was measured using a $\varsigma$-potential analyzer (Zetasizer, Nano ZS, Malvern Instruments Ltd., Worcestershire, UK). In the case of $\varsigma$-potential measurements, the emulsions were diluted $(1 / 100)$ with deionized water or phosphate buffer solutions $(10 \mathrm{mM})$ of appropriate $\mathrm{pH}$ and salt concentration, prior to analysis, to prevent multiple scattering effects. When using the Beckman Coulter, the emulsions were directly injected into the measurement module without dilution.

\subsection{Data Analysis}

All measurements were performed in duplicate using two independently prepared samples. The reported values represent means and standard deviations. The measurements were subjected to analysis of variance (ANOVA) using the "Tukey" test to assess significant differences among variables at 95\% confidence level using Excel (Microsoft, Redmond, WA, USA).

\section{Results and Discussion}

3.1. Physicochemical Properties of OOC Extracts

3.1.1. Surface-Active Composition

Proteins and saponins are known to have surface-active properties due to the presence of hydrophilic and hydrophobic moieties in their chemical structures [20,21]. Polyphenols are also known to exhibit surface-active properties, contributing to the formation and 
stabilization of $\mathrm{O} / \mathrm{W}$ emulsions [22]. Moreover, they can act as antioxidants in many food products and beverages, providing additional properties such as chemical stability and antioxidant activity to the prepared emulsions [23]. In this section, we evaluated the effect of extraction solvent on the concentration of proteins, saponins and phenolic compounds in OOC extracts. As shown in Table 1, increasing the concentration of ethanol did not have a strong effect on protein and saponin contents; even in the absolute ethanol extract where it was expected that the concentration of proteins would be reduced appreciably due to protein precipitation, the concentration was close to that obtained by the water extract. Phenolic compound concentration, on the other hand, was appreciably reduced in the absolute ethanol extract (Table 1).

Table 1. Extraction yields (EY) and content in surface-active components (\%, w/w) of olive oil cake (OOC) extracts prepared using various aqueous-ethanolic solvent mixtures. Means in the same line followed by the same letter are not significantly different $(\alpha=0.05)$.

\begin{tabular}{ccccccc}
\hline & OOC 0\% & OOC 20\% & OOC 40\% & OOC 60\% & OOC 80\% & OOC 100\% \\
\hline EY \% $(w / w)$ & $10.2 \pm 0.9^{\mathrm{de}}$ & $11.6 \pm 1.1^{\mathrm{cd}}$ & $9.6 \pm 0.9^{\mathrm{e}}$ & $12.0 \pm 1.2^{\mathrm{c}}$ & $16.6 \pm 1.9^{\mathrm{b}}$ & $22.4 \pm 2.3^{\mathrm{a}}$ \\
Proteins & $1.79 \pm 0.14^{\mathrm{c}}$ & $2.86 \pm 0.12^{\mathrm{a}}$ & $2.27 \pm 0.19^{\mathrm{b}}$ & $2.23 \pm 0.14^{\mathrm{b}}$ & $2.19 \pm 0.14^{\mathrm{b}}$ & $1.20 \pm 0.17^{\mathrm{d}}$ \\
Saponins & $7.80 \pm 0.38^{\mathrm{c}}$ & $8.07 \pm 0.58^{\mathrm{bc}}$ & $8.71 \pm 0.67^{\mathrm{b}}$ & $9.01 \pm 1.07^{\mathrm{ab}}$ & $8.38 \pm 0.86^{\mathrm{bc}}$ & $9.29 \pm 0.68^{\mathrm{a}}$ \\
Polyphenols & $4.58 \pm 0.26^{\mathrm{a}}$ & $4.20 \pm 0.22^{\mathrm{a}}$ & $3.23 \pm 0.14^{\mathrm{b}}$ & $4.27 \pm 0.23^{\mathrm{a}}$ & $3.49 \pm 0.11^{\mathrm{b}}$ & $0.72 \pm 0.04^{\mathrm{c}}$ \\
\hline
\end{tabular}

Note: The shared letter(s) in the respective column indicate(s) no significant difference $(p<0.05)$.

\subsubsection{Particle Size Distribution}

Proteins, saponins and phenolic compounds can interact by the effect of low molecular forces such as hydrogen bonds, electrostatic and hydrophobic interactions, in the bulk water phase, prior to adsorption or directly at the oil/water interface following adsorption of the slowly diffusing component on the pre-adsorbed layer of the other component [24-27]. To evaluate the structural organization of surface-active components in our extracts, and to gain better insight about their adsorption mechanisms, we evaluated the particle size and particle size distribution of aqueous phases containing OOC extracts. As shown in Figure 1, OOC extracts aqueous solutions $(1 \%, w / w)$ had broad particle size distributions with average particle sizes of more than $100 \mathrm{~nm}$. Moreover, except for $40 \%$ (w/w) aqueous ethanol extract, all samples had no particles smaller than $50 \mathrm{~nm}$, indicating the presence of relatively large structures. Small molecule surfactants, such as saponins, form micelles of approximately $10 \mathrm{~nm}$ [28]. We suggest, therefore, that OOC extracts contain relatively large aggregates that result from the intermolecular interactions between various surface-active components, including proteins, saponins and phenolic compounds.

\subsubsection{Interfacial Activity}

Interfacial tension of emulsifiers plays an important role in determining their ability to form and stabilize emulsions. Usually, the lower the interfacial tension is, the greater the emulsifying properties are [29]. We measured, therefore, the interfacial tension of OOC extracts at the oil/water interface and compared their surface-active properties to commonly used emulsifiers. As shown in Figure 2, all extracts reduced their interfacial tension at the soybean oil/water interface, independently of extract composition. Extract 40\% (w/w) aqueous-ethanol, for example, reduced its interfacial tension to approximately $13 \mathrm{mN} \mathrm{m}^{-1}$, while $80 \%(w / w)$ aqueous ethanolic extract was less efficient at about $16 \mathrm{mN} \mathrm{m}^{-1}$. These values are lower than the ones recorded from either non-composted or composted olive waste derived extracts $[15,17]$. They are in the same range, however, of previously evaluated extracts from sugar beet, bagasse, liquorice and argan press-cake extracts as well as purified natural emulsifiers, including proteins, saponins and phospholipids [7,10,12,30-33]. 

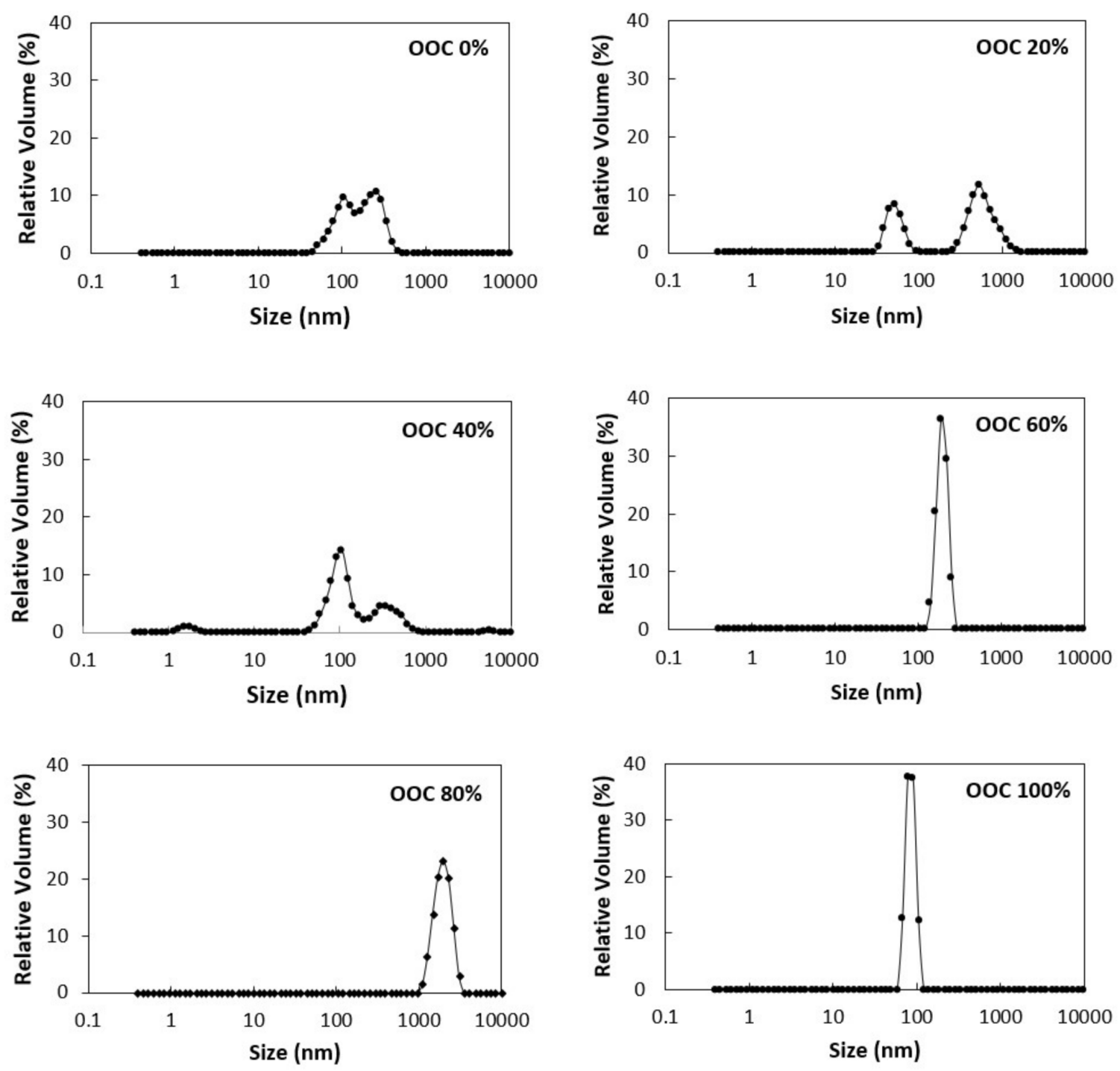

Figure 1. Particle size distribution of aqueous phases containing $1 \%(w / w)$ OOC extracts.

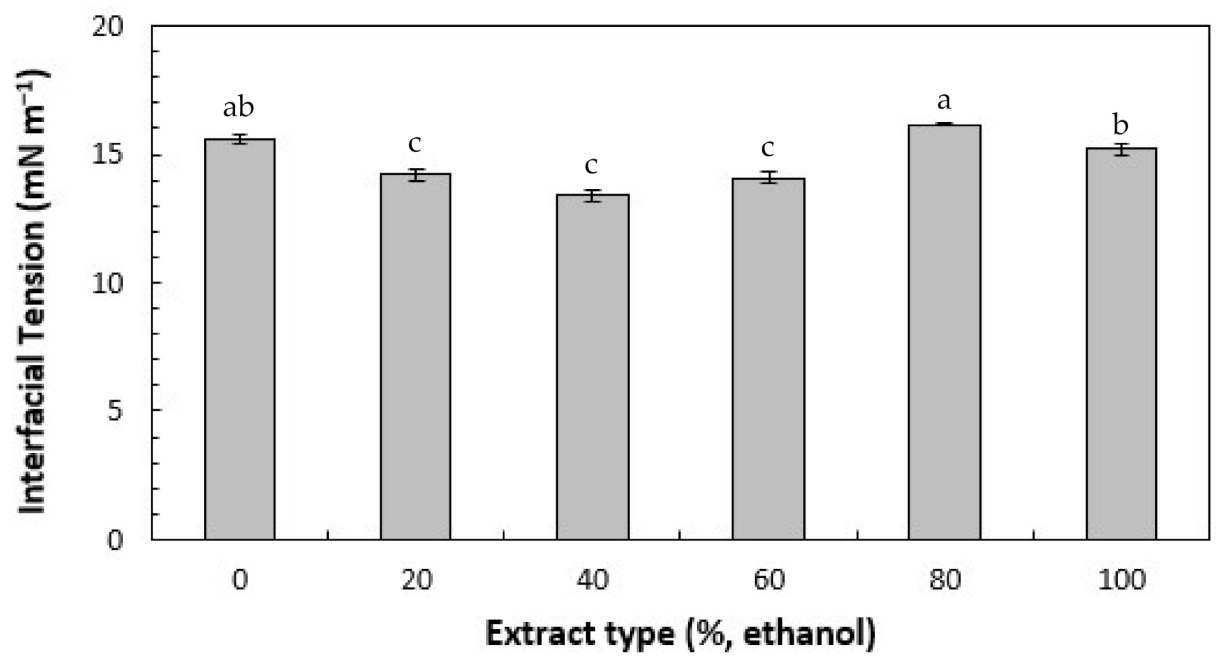

Figure 2. Interfacial tension of aqueous phases containing crude OOC extracts $(1 \%, w / w)$. The interfacial tension between soybean oil and Milli-Q water was approximately $26 \mathrm{mN} \mathrm{m}^{-1}$. The shared letter(s) indicate(s) no significant difference $(p<0.05)$. 


\subsection{Effect of Extract Type on the Formation Characteristics of $O / W$ Emulsion}

\subsubsection{Droplet Size}

In order to evaluate the emulsifying performance of OOC extracts, $\mathrm{O} / \mathrm{W}$ emulsions were prepared using aqueous solutions $(1 \%, w / w)$ of each extract and $5 \%(w / w)$ soybean oil at standard homogenization conditions (100 MPa, four passes). Except for emulsions prepared using absolute ethanol extract, which showed immediate oiling-off after homogenization, all emulsions prepared using OOC extracts were successfully produced with average droplet sizes $\left(d_{4,3}\right)$ of $0.3-0.4 \mu \mathrm{m}$ (Figure 3a). When stored at $5^{\circ} \mathrm{C}$, the emulsions showed no evidence of droplet growth or phase separation for up to 15 days with a main peak around 0.4-0.6 $\mu \mathrm{m}$ (Figure 4). At $25^{\circ} \mathrm{C}$, the peak around $0.4 \mu \mathrm{m}$ was maintained but for the emulsions prepared using $0,20,40$ and $60 \%(w / w)$ ethanol-to-water-ratios, droplet growth occurred with the emergence of lesser peaks around 4.5-15 $\mu \mathrm{m}$. Interestingly, emulsions prepared using $80 \%(w / w)$ aqueous ethanolic extract were stable at all studied temperatures despite their close surface-active composition and interfacial activity to other extracts. With a main peak around $0.4 \mu \mathrm{m}$ and a lesser peak around $0.08 \mu \mathrm{m}$ (Figure 4), OOC $80 \%$ appears to be a better emulsifier and was used, therefore, for further experiments.

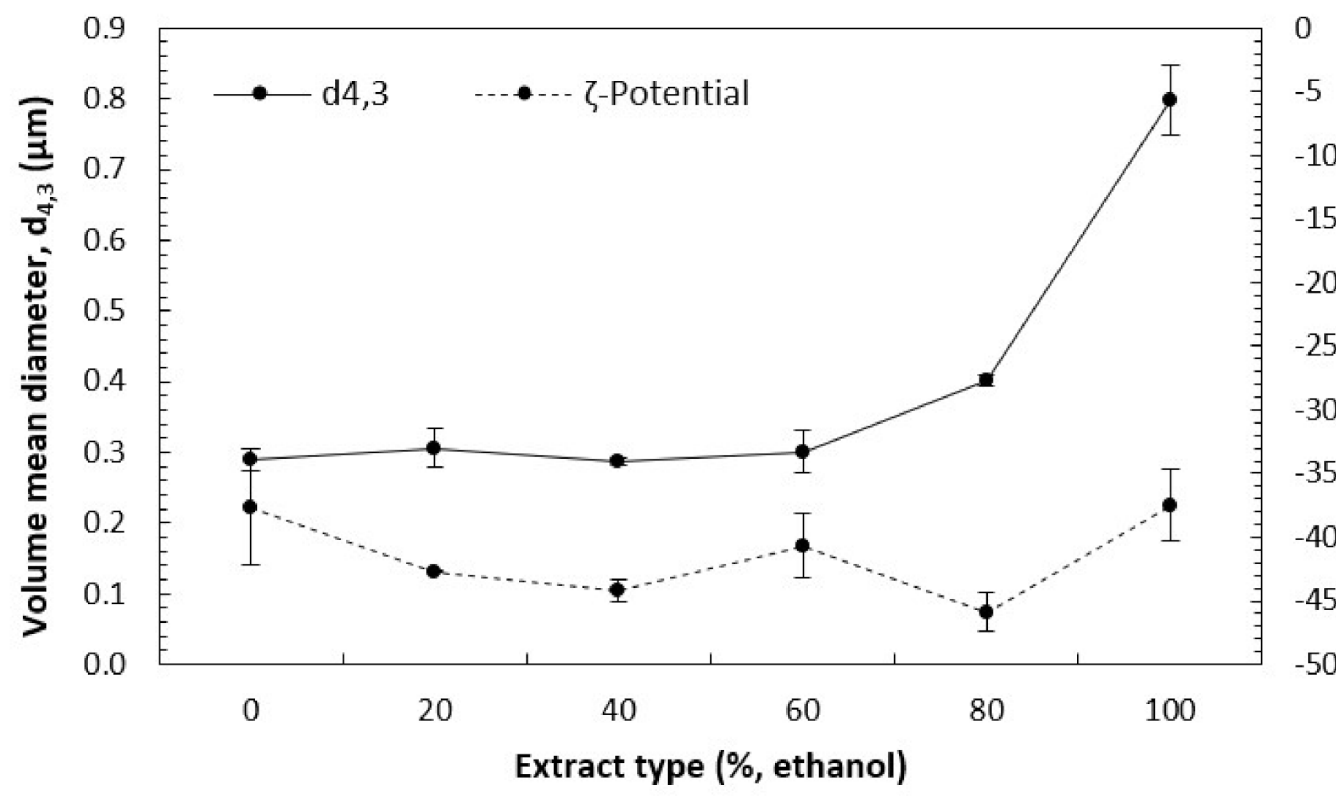

(a)

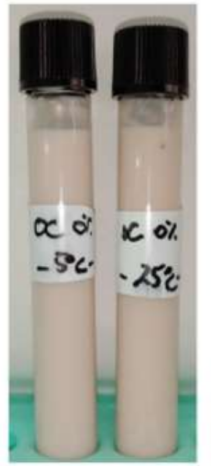

OOC $0 \%$

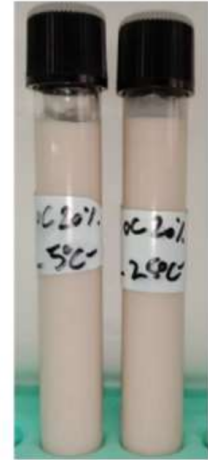

OOC $20 \%$

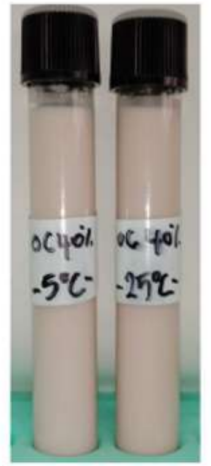

OOC $40 \%$

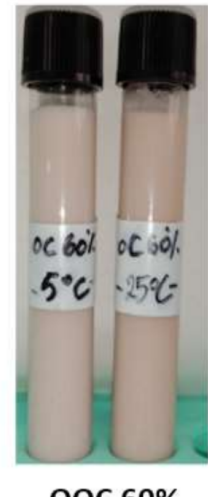

$00 \mathrm{OC} 6 \%$

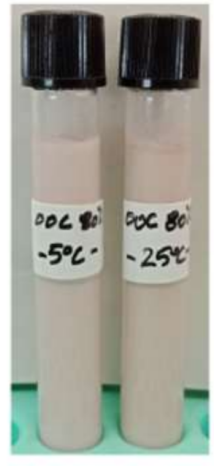

OOC $80 \%$

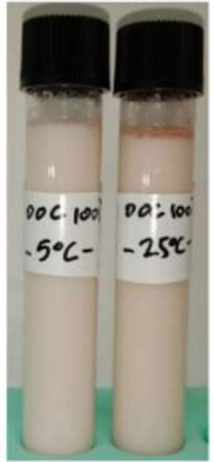

OOC $100 \%$

(b)

Figure 3. (a) Volume mean droplet diameter $\left(d_{4,3}\right)$ and $\zeta$-potential of soybean oil-in-water $(\mathrm{O} / \mathrm{W})$ emulsions prepared using OOC aqueous ethanolic extracts, by high-pressure homogenization (100 MPa, 4 passes). (b) Visual appearance of OOC extract-stabilized emulsions after 15 days of storage at $5^{\circ} \mathrm{C}$ or $25^{\circ} \mathrm{C}$. 

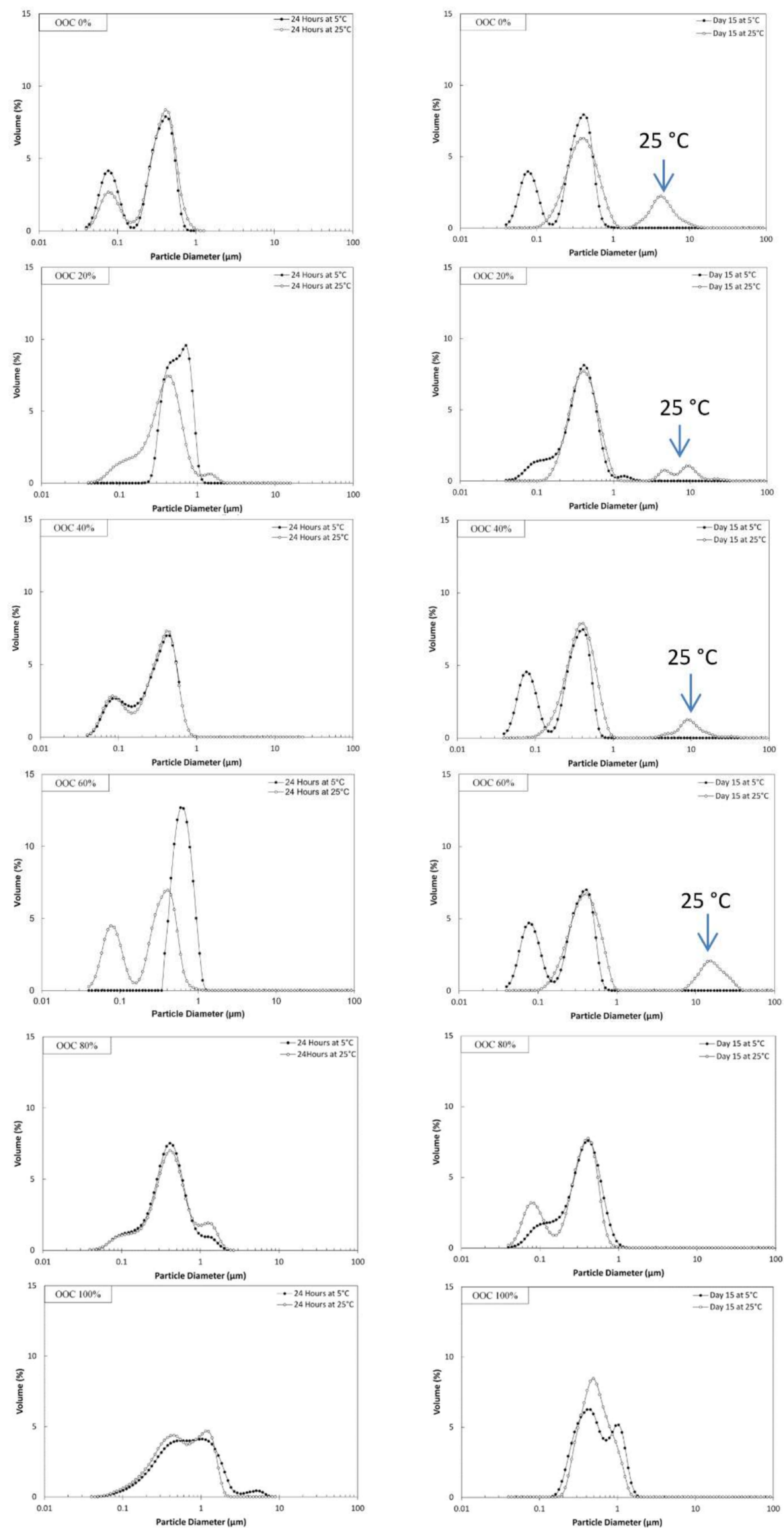

Figure 4. Droplet size distributions of emulsions prepared using 1\% (w/w) OOC extracts and 5\% $(w / w)$ soybean oil, by high-pressure homogenization (100 MPa, 4 passes). 
Previous studies have evaluated the emulsification capacity of extracts obtained from composted olive oil waste materials $[16,17]$. The studied emulsifiers produced larger droplets with a main peak around 2 to $3 \mu \mathrm{m}$ and a relatively constant droplet size distribution for 15 days of storage. The emulsifiers studied in this work encourage, therefore, the use of crude extracts, instead of time-consuming composting materials to produce stable $\mathrm{O} / \mathrm{W}$ emulsions with smaller droplet sizes and a similar period of storage.

\subsubsection{Droplet Surface Charge}

The surface charge of emulsion droplets plays an important role in the formation and stabilization of emulsions. In general, a higher $\zeta$-potential means that the emulsifier layer yields more repulsive forces between emulsion droplets, thus preventing their coalescence. A neutral $\zeta$-potential, on the other hand, means that the emulsifier covered interfaces are more likely to destabilize, resulting in the formation of larger particles [33]. As shown in Figure 3a, all emulsions prepared using OOC extracts displayed a strong negative $\zeta$-potential, independently of their stability characteristics. The $80 \%(w / w)$ aqueous ethanol extract, for example, provided a $\zeta$-potential of $-45.9 \mathrm{mV}$, in agreement with its good emulsion-stabilizing properties. Absolute ethanol extract, on the other hand, presented a $\zeta$-potential of $-37.5 \mathrm{mV}$, despite its limited emulsifying ability.

Carboxylic acid groups with typical pKa values of $\sim 3.5$ may be responsible for the negative $\zeta$-potentials of emulsions stabilized by OOC extracts [3]. This group would be fully charged $\left(\mathrm{COO}^{-}\right)$at $\mathrm{pH} 7$, hence the strong negative charge of emulsion droplets. Proteins can be also responsible for the negative surface charge observed in our conditions as they usually show negative $\zeta$-potentials of approximately $-40 \mathrm{mV}$ at $\mathrm{pH} 7[1,34]$.

\subsection{Effect of OOC $80 \%$ Extract Concentration and Oil Mass Fraction on Emulsion Formation}

The $d_{4,3}$ of emulsions gradually decreased upon increasing $80 \%(w / w)$ aqueous ethanolic extract concentration from 0.1 to $1 \%(w / w)$. Further increase in extract concentration appreciably increased the droplet size of emulsions and resulted in visible creaming at $5 \%(w / w)$ (Figure $5 a, b)$. The ability of an emulsifier to produce small droplet size emulsions depends on (i) its ability to reduce the interfacial tension, (ii) the speed at which it adsorbs on the droplets' interface and (iii) its effectiveness to produce repulsive forces during homogenization [3,35]. Lower concentrations of OOC extract were insufficient, therefore, to reduce interfacial tension and/or stabilize the newly generated interfaces, while higher concentrations increased the contents of emulsion destabilizing agents (e.g., minerals) in the emulsions.

Increasing oil mass fraction from 2.5 to $10 \%(w / w)$ also increased the droplet size of OOC-stabilized emulsions (Figure $5 \mathrm{c}$ ). This suggests that relatively high emulsifier-tooil ratios are needed to produce small droplet size emulsions using the present extract. Moreover, further increase in oil concentration increases the viscosity of emulsions, which affects their disruption efficiency during homogenization [35]. Overall, small droplet size $\mathrm{O} / \mathrm{W}$ emulsions can be prepared using $1 \%(w / w)$ OOC extract and $5 \%(w / w)$ soybean oil by high-pressure homogenization (100 $\mathrm{MPa}$, four passes). We proceeded, therefore, to evaluate the stability characteristics of these emulsions at different stress conditions to determine their potential application.

\subsection{Effect of Stress Conditions on OOC $80 \%$ Extract Stabilized Emulsions}

Emulsions prepared using OOC $80 \%(w / w)$ aqueous ethanol extract were stable from $\mathrm{pH} 5$ to 10 with average $d_{4,3}$ of $0.3 \mu \mathrm{m}$. Further decrease in $\mathrm{pH}$ gradually increased the droplet size of emulsions or resulted in excessive creaming at $\mathrm{pH} 3$ and 2 (Figure 6). Increasing $\mathrm{NaCl}$ concentration also reduced the stability of emulsions as indicated by droplet size measurements and visual appearance. The $d_{4,3}$ increased to $6.2 \mu \mathrm{m}$ at $100 \mathrm{mM}$ and visible creaming was observed from $25 \mathrm{mM}$ (Figure 7). These results agreed with the $\zeta$-potential measurements of emulsions, which gradually decreased upon reducing the $\mathrm{pH}$ or increasing $\mathrm{NaCl}$ concentration (Figures 6 and 7). 
Saponins show a pKa of approximately 3.25 and, therefore, reducing the $\mathrm{pH}$ below this value leads to screening the surface charge of emulsions droplets [2]. Moreover, electrostatic screening of the negative charge of saponins can affect their intermolecular interaction with other components, including proteins, affecting the interfacial layer composition of emulsions droplets. The stabilization mechanism of OOC $80 \%$ extract-stabilized emulsions depends, therefore, importantly on electrostatic repulsion due to the adsorption of ionizable surface active components with ionizable groups, such as saponins. The contribution of other components (e.g., proteins) to emulsions stability is also suggested, explaining their resistance to complete phase separation (oiling-off) at extreme environmental conditions by providing stronger interfacial coverage.

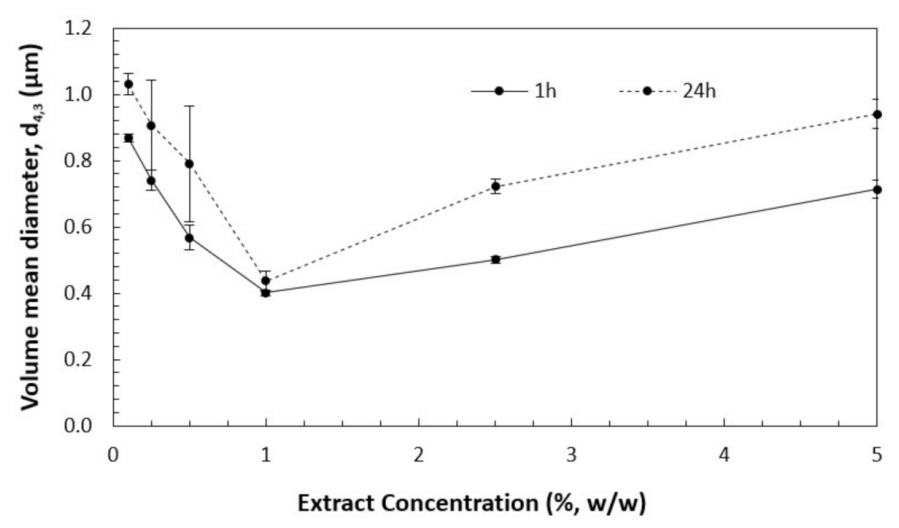

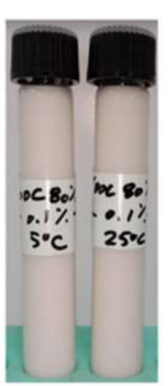

$0.1 \%$

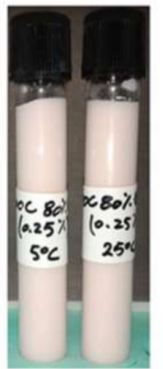

$0.25 \%$

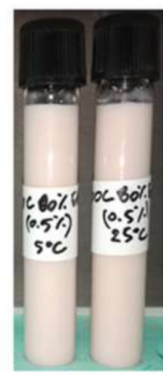

$0.5 \%$

(a)

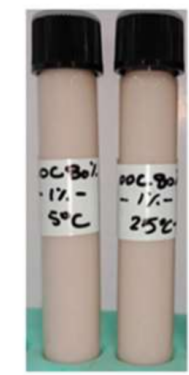

$1 \%$

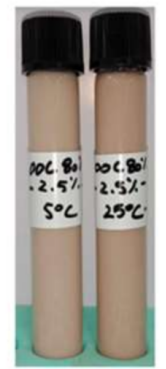

$2.5 \%$

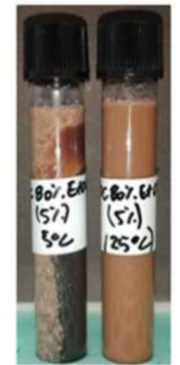

$5 \%$

(b)

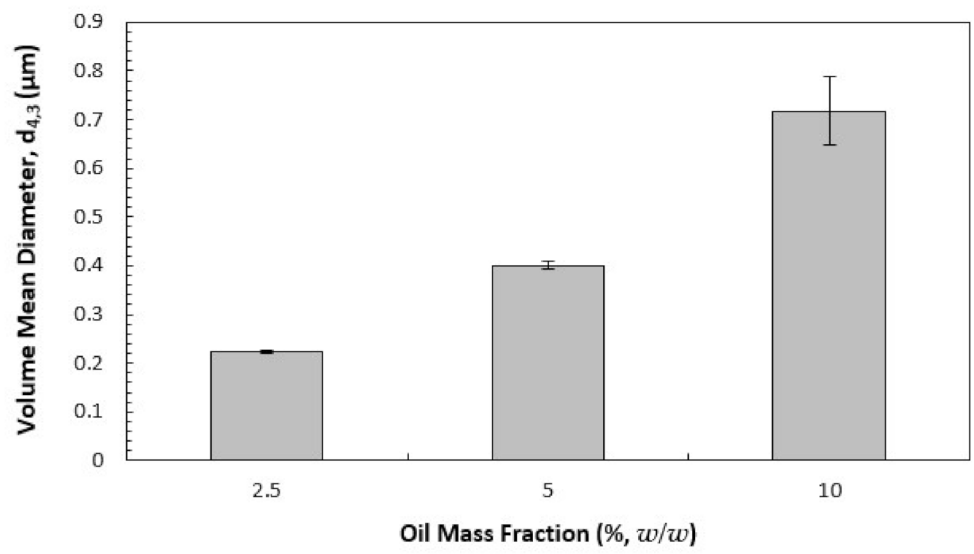

(c)

Figure 5. (a) Effect of OOC $80 \%(w / w)$ aqueous ethanolic extract concentration on the volume mean droplet diameter of emulsions after 1 and $24 \mathrm{~h}$ of storage at $5{ }^{\circ} \mathrm{C}$; (b) effect of OOC $80 \%$ extract concentration on the visual appearance of emulsions after $24 \mathrm{~h}$ of storage at $5^{\circ} \mathrm{C}$. (c) Effect of oil mass fraction on the mean droplet size of emulsions after $24 \mathrm{~h}$ of storage at $5{ }^{\circ} \mathrm{C}$. 


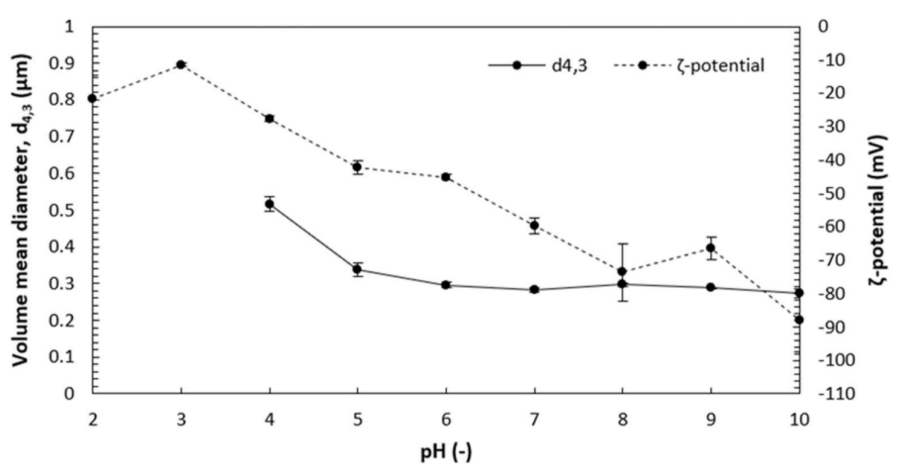

(a)

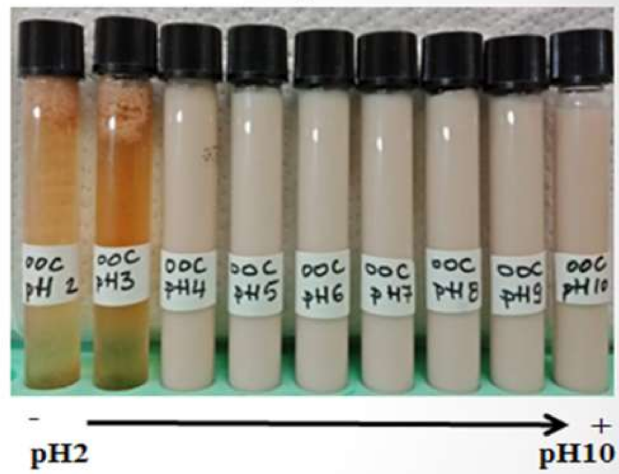

(b)

Figure 6. (a) Effect of $\mathrm{pH}$ on the volume mean droplet diameter $\left(d_{4,3}\right), \zeta$-potential and (b) visual appearance of $\mathrm{O} / \mathrm{W}$ emulsions prepared using OOC $80 \%$ aqueous ethanolic extract.

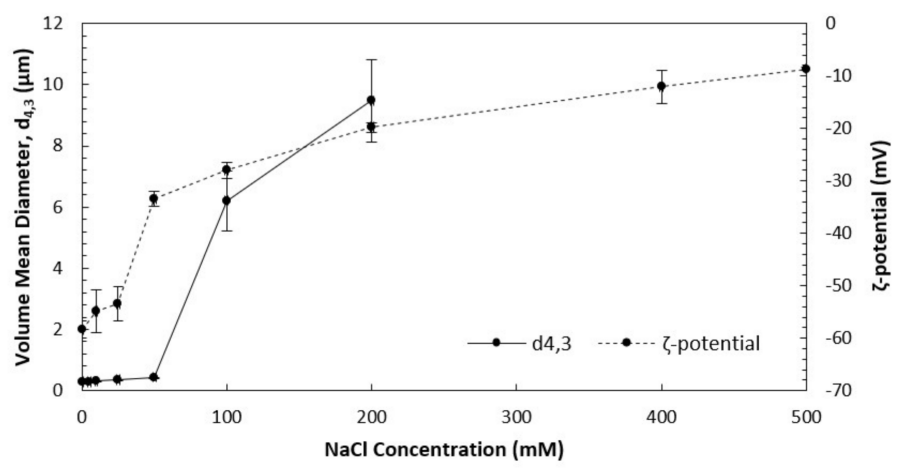

(a)

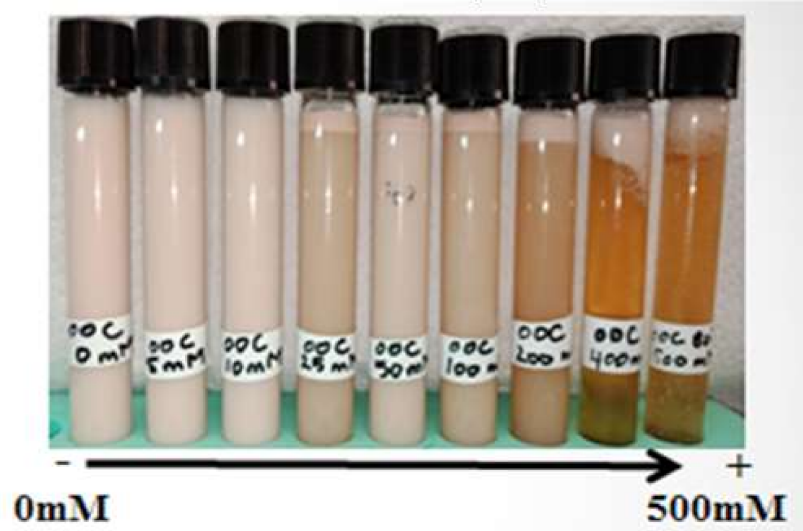

(b)

Figure 7. (a) Effect of $\mathrm{NaCl}$ concentration on the volume mean droplet diameter $\left(d_{4,3}\right)$, $\zeta$-potential and (b) visual appearance of $\mathrm{O} / \mathrm{W}$ emulsions prepared using OOC $80 \%$ aqueous ethanolic extract. 
The $d_{4,3}$ of OOC $80 \%$ extract-stabilized emulsions did not change after 30 days of storage at different temperatures (Table 2), thus its potential use for the preparation of stable $\mathrm{O} / \mathrm{W}$ emulsions by high-pressure homogenization.

Table 2. Volume mean droplet diameter $(\mu \mathrm{m})$ changes of emulsions prepared using $1 \%(w / w)$ OOC $80 \%$ extract and $5 \%(w / w)$ soybean oil, by high-pressure homogenization.

\begin{tabular}{cccc}
\hline & $\mathbf{5}^{\circ} \mathbf{C}$ & $\mathbf{2 5}{ }^{\circ} \mathbf{C}$ & $\mathbf{5 0}{ }^{\circ} \mathbf{C}$ \\
\hline Day 1 & 0.437 & 0.405 & 0.401 \\
Day 7 & 0.416 & 0.440 & 0.470 \\
Day 15 & 0.427 & 0.405 & 0.481 \\
Day 30 & 0.394 & 0.387 & 0.426 \\
\hline
\end{tabular}

\section{Conclusions}

The present work suggests a novel approach for using crude aqueous-ethanolic extracts from untreated olive oil cake to produce stable $\mathrm{O} / \mathrm{W}$ emulsions with smaller droplet sizes and for an extended period of storage. OOC extracts successfully formed emulsions with average droplet sizes $\left(d_{4,3}\right)$ of $0.28-0.4 \mu \mathrm{m}$. OOC $80 \%(w / w)$ aqueous ethanolic extract was selected, as it provided the best storage stability for up to 15 days at $25^{\circ} \mathrm{C}$. Our results clearly showed that this extract could produce emulsions with good physical stability at a wide range of $\mathrm{pH}(5-10)$ and when stored at 5,25 and $50{ }^{\circ} \mathrm{C}$ for 30 days. However, the emulsions were highly unstable at extreme acidic $\mathrm{pH}(<4)$, and at increased ionic strengths $(\geq 25 \mathrm{mM})$. The main stabilization mechanism is believed to be mainly electrostatic, likely due to the presence of surface-active compounds with ionizable groups such as saponins. In future studies, it would be helpful to extend this work by evaluating other parameters, such as the taste profile, the toxicity, the cost, and the reliability of supply to encourage the application of this extract as a food emulsifier.

Author Contributions: Conceptualization, F.F., A.H. and M.N.; methodology, F.F.; software, F.F.; validation, A.H., M.A.N., and M.N.; formal analysis, F.F.; investigation, F.F. and F.B.; resources, M.N.; data curation, F.F.; writing-original draft preparation, F.F.; writing-review and editing, N.T.; visualization, F.F.; supervision, N.T.; project administration, M.N., A.H. and H.I.; funding acquisition, M.N. All authors have read and agreed to the published version of the manuscript.

Funding: This research was funded by the Japan Science and Technology Agency and the Japan International Cooperation Agency under the framework of SATREPS project [grant number JPMJSA1506].

Institutional Review Board Statement: Not applicable.

Informed Consent Statement: Not applicable.

Data Availability Statement: Data sharing not applicable.

Acknowledgments: This research was financially supported by the Science and Technology Research Partnership for Sustainable Development-SATREPS project, from JICA/JST, Japan.

Conflicts of Interest: The authors declare no conflict of interest.

\section{References}

1. McClements, D.J. Food Emulsions Principles, Practices, and Techniques, 3rd ed.; CRS Press: Boca Raton, FL, USA, 2015; ISBN 9781498726696.

2. Ozturk, B.; McClements, D.J. Progress in natural emulsifiers for utilization in food emulsions. Curr. Opin. Food Sci. 2016, 7, 1-6. [CrossRef]

3. Yang, Y.; Leser, M.E.; Sher, A.A.; McClements, D.J. Formation and stability of emulsions using a natural small molecule surfactant: Quillaja saponin (Q-Naturale ${ }^{\circledR}$ ). Food Hydrocoll. 2013, 30, 589-596. [CrossRef]

4. Melanie, H.; Taarji, N.; Zhao, Y.; Khalid, N.; Neves, M.A.; Kobayashi, I.; Tuwo, A.; Nakajima, M. Formulation and characterisation of $\mathrm{O} / \mathrm{W}$ emulsions stabilised with modified seaweed polysaccharides. Int. J. Food Sci. Technol. 2020, 55, 211-221. [CrossRef] 
5. Chen, Z.; Shu, G.; Taarji, N.; Barrow, C.J.; Nakajima, M.; Khalid, N.; Neves, M.A. Gypenosides as natural emulsifiers for oil-in-water nanoemulsions loaded with astaxanthin: Insights of formulation, stability and release properties. Food Chem. 2018, 261. [CrossRef]

6. Bouhoute, M.; Taarji, N.; de Oliveira Felipe, L.; Habibi, Y.; Kobayashi, I.; Zahar, M.; Isoda, H.; Nakajima, M.; Neves, M.A. Microfibrillated cellulose from Argania spinosa shells as sustainable solid particles for O/W Pickering emulsions. Carbohydr. Polym. 2021, 251, 116990. [CrossRef]

7. Ralla, T.; Salminen, H.; Edelmann, M.; Dawid, C.; Hofmann, T.; Weiss, J. Sugar Beet Extract (Beta vulgaris L.) as a New Natural Emulsifier: Emulsion Formation. J. Agric. Food Chem. 2017, 65, 4153-4160. [CrossRef]

8. Ralla, T.; Herz, E.; Salminen, H.; Edelmann, M.; Dawid, C.; Hofmann, T.; Weiss, J. Emulsifying Properties of Natural Extracts from Panax ginseng L. Food Biophys. 2017, 12, 479-490. [CrossRef]

9. Ralla, T.; Salminen, H.; Edelmann, M.; Dawid, C.; Hofmann, T.; Weiss, J. Oat bran extract (Avena sativa L.) from food by-product streams as new natural emulsifier. Food Hydrocoll. 2018, 81, 253-262. [CrossRef]

10. Taarji, N.; Rabelo da Silva, C.A.; Khalid, N.; Gadhi, C.; Hafidi, A.; Kobayashi, I.; Neves, M.A.; Isoda, H.; Nakajima, M. Formulation and stabilization of oil-in-water nanoemulsions using a saponins-rich extract from argan oil press-cake. Food Chem. 2018, 246, 457-463. [CrossRef]

11. Bouhoute, M.; Taarji, N.; Vodo, S.; Kobayashi, I.; Zahar, M.; Isoda, H.; Nakajima, M.; Neves, M.A. Formation and stability of emulsions using crude extracts as natural emulsifiers from Argan shells. Colloids Surf. A Physicochem. Eng. Asp. 2020, $591,124536$. [CrossRef]

12. Vodo, S.; Taarji, N.; Bouhoute, M.; de Oliveira Felipe, L.; Neves, M.A.; Kobayashi, I.; Uemura, K.; Nakajima, M. Potential of bagasse obtained using hydrothermal liquefaction pre-treatment as a natural emulsifier. Int. J. Food Sci. Technol. 2020. [CrossRef]

13. Fernández-Bolaños, J.; Rodríguez, G.; Gómez, E.; Guillén, R.; Jiménez, A.; Heredia, A.; Rodríguez, R. Total recovery of the waste of two-phase olive oil processing: Isolation of added-value compounds. J. Agric. Food Chem. 2004, 52, 5849-5855. [CrossRef]

14. Mirabella, N.; Castellani, V.; Sala, S. Current options for the valorization of food manufacturing waste: A review. J. Clean. Prod. 2014, 65, 28-41. [CrossRef]

15. Filotheou, A.; Ritzoulis, C.; Avgidou, M.; Kalogianni, E.P.; Pavlou, A.; Panayiotou, C. Novel emulsifiers from olive processing solid waste. Food Hydrocoll. 2015, 48, 274-281. [CrossRef]

16. Koliastasi, A.; Kompothekra, V.; Giotis, C.; Moustakas, A.K. Emulsifiers from Partially Composted Olive Waste. Foods 2019,8 , 271. [CrossRef]

17. Koliastasi, A.; Kompothekra, V.; Giotis, C.; Moustakas, A.K.; Skotti, E.P.; Gerakis, A.; Kalogianni, E.P.; Georgiou, D.; Ritzoulis, C. Food Hydrocolloids Novel emulsi fi ers from olive mill compost. Food Hydrocoll. 2020, 99, 105373. [CrossRef]

18. Zhaobao, X.; Chunhong, T.; Gang, C.; Zhisong, S. Studied on corlorimetric determination of oleanolic acid in Chinese quince. Nat. Prod. Res. Dev. 2001, 13, 23-26.

19. Rabelo, C.A.S.; Taarji, N.; Khalid, N.; Kobayashi, I.; Nakajima, M.; Neves, M.A. Formulation and characterization of water-in-oil nanoemulsions loaded with açaí berry anthocyanins: Insights of degradation kinetics and stability evaluation of anthocyanins and nanoemulsions. Food Res. Int. 2018, 106. [CrossRef]

20. Oleszek, W.; Hamed, A. Saponin-Based Surfactants. In Surfactants from Renewable Resources, 1st ed.; Wiley: Hoboken, NJ, USA, 2010; pp. 239-249.

21. Lam, R.S.H.; Nickerson, M.T. Food proteins: A review on their emulsifying properties using a structure-function approach. Food Chem. 2013, 141, 975-984. [CrossRef]

22. Souilem, S.; Kobayashi, I.; Neves, M.A.; Jlaiel, L.; Isoda, H.; Sayadi, S.; Nakajima, M. Interfacial characteristics and microchannel emulsification of oleuropein-containing triglyceride oil-water systems. Food Res. Int. 2014, 62, 467-475. [CrossRef]

23. Di Mattia, C.D.; Sacchetti, G.; Mastrocola, D.; Sarker, D.K.; Pittia, P. Surface properties of phenolic compounds and their influence on the dispersion degree and oxidative stability of olive oil O/W emulsions. Food Hydrocoll. 2010, 24, 652-658. [CrossRef]

24. Piotrowski, M.; Lewandowska, J.; Wojciechowski, K. Biosurfactant-Protein Mixtures: Quillaja Bark Saponin at Water/Air and Water/Oil Interfaces in Presence of $\beta$-Lactoglobulin. J. Phys. Chem. B 2012, 116, 4843-4850. [CrossRef]

25. Wojciechowski, K.; Kezwon, A.; Lewandowska, J.; Marcinkowski, K. Effect of $\beta$-casein on surface activity of Quillaja bark saponin at fluid/fluid interfaces. Food Hydrocoll. 2014, 34, 208-216. [CrossRef]

26. Wojciechowski, K.; Piotrowski, M.; Popielarz, W.; Sosnowski, T.R. Short- and mid-term adsorption behaviour of Quillaja Bark Saponin and its mixtures with lysozyme. Food Hydrocoll. 2011, 25, 687-693. [CrossRef]

27. Bandyopadhyay, P.; Ghosh, A.K.; Ghosh, C. Recent developments on polyphenol-protein interactions: Effects on tea and coffee taste, antioxidant properties and the digestive system. Food Funct. 2012, 3, 592-605. [CrossRef]

28. Mitra, S.; Dungan, S.R. Micellar Properties of Quillaja Saponin. 1. Effects of Temperature, Salt, and pH on Solution Properties. J. Agric. Food Chem. 1997, 45, 1587-1595. [CrossRef]

29. Stamkulov, N.S.; Mussabekov, K.B.; Aidarova, S.B.; Luckham, P.F. Stabilisation of emulsions by using a combination of an oil soluble ionic surfactant and water soluble polyelectrolytes. I: Emulsion stabilisation and Interfacial tension measurements. Colloids Surf. A Physicochem. Eng. Asp. 2009, 335, 103-106. [CrossRef]

30. Taarji, N.; Bouhoute, M.; Fainassi, F.; Hafidi, A.; Kobayashi, I.; Neves, M.A.; Tominaga, K.; Isoda, H.; Nakajima, M. Interfacial and emulsifying properties of purified glycyrrhizin and non-purified glycyrrhizin-rich extracts from liquorice root (Glycyrrhiza glabra). Food Chem. 2021, 337, 127949. [CrossRef] 
31. McClements, D.J.; Gumus, C.E. Natural emulsifiers-Biosurfactants, phospholipids, biopolymers, and colloidal particles: Molecular and physicochemical basis of functional performance. Adv. Colloid Interface Sci. 2016, 234, 3-26. [CrossRef]

32. Ogino, K.; Onishi, M. Interfacial action of natural surfactants in oil/water systems. J. Colloid Interface Sci. 1981, 83, 18-25. [CrossRef]

33. Lu, G.W.; Gao, P. CHAPTER 3-Emulsions and Microemulsions for Topical and Transdermal Drug Delivery. In Personal Care E Cosmetic Technology; William Andrew Publishing: Boston, MA, USA, 2010; pp. 59-94. ISBN 978-0-8155-2025-2.

34. Karaca, A.C.; Low, N.; Nickerson, M. Emulsifying properties of chickpea, faba bean, lentil and pea proteins produced by isoelectric precipitation and salt extraction. Food Res. Int. 2011, 44, 2742-2750. [CrossRef]

35. Baret, J.-C.; Kleinschmidt, F.; El Harrak, A.; Griffiths, A.D. Kinetic Aspects of Emulsion Stabilization by Surfactants: A Microfluidic Analysis. Langmuir 2009, 25, 6088-6093. [CrossRef] [PubMed] 